7. Reprod. Fert. (1975) 45, 189-192

\title{
CONCEPTION RATES AND RELATED DATA USING FROZEN DOG SEMEN
}

\author{
S. W. J. SEAGER, G. G. PLATZ AND W. S. FLETCHER* \\ Texas A $\Xi M$ University/Baylor College of Medicine, Institute of Comparative Medicine, \\ Houston, Texas 77025, and \\ * Department of Surgery, University of Oregon Medical School, \\ Portland, Oregon 97201, U.S.A.
}

(Received 25th February 1975)

There is much interest in the United States and other countries by dog breeders, pet owners, veterinarians and research workers who realize the great potential for the use of frozen semen. This potential is comparable to that already achieved in the cattle breeding industry.

Since the first successful pregnancy utilizing frozen dog semen (Seager, 1969), work on aspects of the freezing of dog semen has continued as part of a study of dog reproductive physiology, and parameters of semen collection, evaluation, freezing and artificial insemination have been established.

This study was undertaken to obtain a conception rate in dogs with frozen semen comparable to that obtained by the use of fresh semen and natural breeding. At the same time, data on the normality of the offspring at birth, sex ratios, birth weights and litter size were collected for comparison. Success in one particular breed of dog does not automatically guarantee success with all breeds. However, data collected to date at this laboratory suggest that it is feasible to freeze the semen from all dog breeds.

The breeds of dog used in this study were Labrador retrievers, crossbreeds and Beagles. The Labradors and crossbreeds were bred at the University of Oregon Medical School Research Farm, and the Beagles were mainly purchased from commercial suppliers. Eighteen Labrador males, four crossbreed males and eight Beagle males were used for semen collection, freezing and artificial insemination in this study. The dogs were housed in wire-enclosed runs with a gravel floor and allowed free access to dry kibble food (Blue Mountain Dog Food, Hervin Company, Tualatin, Oregon). Bitches were checked for oestrus by swabbing the vagina three times/week. Day 1 of oestrus was the first day that a blood-stained vaginal discharge was detected.

A teaser bitch was used to stimulate the male and ejaculations were collected at least once/week and not more than three times/week. At least 1 day of sexual rest was allowed between collections. The apparatus used routinely for semen collection consisted of a rubber sheath attached to a plastic graduated conical centrifuge tube (Seager \& Fletcher, 1973). The collection methods described by other authors (Harrop, 1956; Bendorf \& Chung, 1958; Kirk, 1959; Gill et al., 1970) have been tested in this laboratory but have not proved as effective as the method described above. 
After semen collection, the volume, colour, viscosity and $\mathrm{pH}$ of the semen and the motility and speed of progression of the spermatozoa were ascertained. Sperm counts were performed using a Coleman Junior II spectrophotometer. After analysis, the diluent, consisting of egg yolk, lactose, glycerin, penicillin and streptomycin (Seager, 1969), was added.

The first dilution was made with semen ( 1 vol.) and diluent ( 1 vol.) at room temperature $\left(22^{\circ} \mathrm{C}\right.$ to $23^{\circ} \mathrm{C}$ ) within 20 min of collection. Each sample was then equilibrated on an aliquot shaker in a $5^{\circ} \mathrm{C}$ cold room for $90 \mathrm{~min}$. A second equal dilution of diluent at $5^{\circ} \mathrm{C}$ was made after $60 \mathrm{~min}$ of the equilibration period. After equilibration, the sample was placed as single drops into holes indented in a block of solid carbon dioxide. Indentations were made using a $30 \times 30 \mathrm{~cm}$ square of $25-\mathrm{mm}$ plywood which had nails $4.8 \mathrm{~mm}$ in diameter driven into one side by means of an air gun and the nail heads removed. The nail board was placed on the solid carbon dioxide and removed when the indentations were approximately $6 \mathrm{~mm}$ in depth. The pellets were subsequently deposited in a shallow bath of liquid nitrogen, then placed in labelled 5 or $10 \mathrm{ml}$ Nalgene vials (Sybron Corporation, Rochester, New York). Holes were punched in the vials to allow them to sink in the liquid nitrogen tank for final storage. To date, a rapid thaw in $2.5 \mathrm{ml}$ of $37^{\circ} \mathrm{C}$ physiological saline has resulted in the best recovery upon thawing.

The pelleting technique used was similar to that described by Nagase \& Niwa (1963) and has been the most successful. Other systems and containers for freezing have been studied and included $0.25-\mathrm{ml}, 0.50-\mathrm{ml}$ and $0.90-\mathrm{ml}$ plastic straws and $1-\mathrm{ml}$ prescored glass vials, but a lower percentage of motile spermatozoa was recovered upon thawing.

The insemination apparatus consisted of a $40.6-\mathrm{cm}$ plastic bovine insemination rod broken in half, a $12 \cdot 7-\mathrm{mm}$ rubber connector and a $10-\mathrm{ml}$ plastic disposable syringe. Most of the bitches were inseminated on Days 10 and 12 of oestrus. Insemination was performed with the rear quarters of the bitch elevated to an angle of $60^{\circ}$, and they were maintained in this position for $5 \mathrm{~min}$ after insemination (Seager \& Fletcher, 1973). The volume of thawed semen artificially inseminated varied from 3.0 to $9.0 \mathrm{ml}$ and the numbers of live motile spermatozoa varied from $150 \times 10^{6}$ to $700 \times 10^{6}$ per insemination.

In this study, conceptions have been obtained with semen stored from 1 day to 35 months before thawing and artificial insemination. There appears to be negligible decrease in sperm survival after more than 8 years' storage at approximately $-196^{\circ} \mathrm{C}$.

Table 1 shows the conception rate, determined at the time of parturition, obtained with semen frozen by the pellet method. The number of puppies born and their birth weights and sex ratios are provided in Table 2. Table 3 compares the results obtained from natural mating and artificial insemination with fresh and frozen semen. The amount of use of each sire in the three groups varied.

In the Oregon Dog Golony, the incidence of birth defects and the general health of the litters resulting from insemination with frozen semen was no greater than those occurring in litters resulting from fresh semen and natural breeding. The postnatal mortality rate I week after birth of the 250 puppies 
from the 61 litters born to bitches inseminated with frozen semen was comparable to that occurring for puppies conceived by natural mating and by artificial insemination with fresh semen (J. W. Templeton, personal communication). The litter sizes from frozen semen in 1969 and 1970 were lower than the average, but they have increased and are now comparable to the two other methods of breeding.

Table 1. Yearly conception rate in dogs after artificial insemination with semen frozen by the pellet method

\begin{tabular}{cccc}
\hline rear & $\begin{array}{c}\text { No. of bitches } \\
\text { inseminated }\end{array}$ & No. pregnant & Pregnancy rate (\%) \\
\hline 1969 & 21 & 2 & $9 \cdot 5$ \\
1970 & 29 & 3 & $10 \cdot 3$ \\
1971 & 20 & 8 & $40 \cdot 0$ \\
1972 & 38 & 25 & $65 \cdot 8$ \\
1973 & 37 & 16 & $43 \cdot 2$ \\
1974 & 11 & 7 & $63 \cdot 6$ \\
\hline
\end{tabular}

Table 2. Data on puppies born to bitches inseminated with frozen semen (1969 to 1974)

\begin{tabular}{|c|c|c|c|c|}
\hline & $\begin{array}{c}\text { No. of } \\
\text { puppies born }\end{array}$ & $\begin{array}{l}\text { Average no. } \\
\text { of pups/litter }\end{array}$ & $\begin{array}{c}\text { Average } \\
\text { birth wt }(\mathrm{g})\end{array}$ & $\begin{array}{c}\text { Sex ratio } \\
(0 ; 0: ?)\end{array}$ \\
\hline \multicolumn{5}{|l|}{ Labrador } \\
\hline Nulliparous & 37 & $3 \cdot 7$ & 473 & $20: 11$ \\
\hline Multiparous & 20 & $4 \cdot 0$ & 444 & $12: 8$ \\
\hline \multicolumn{5}{|l|}{ Crossbreed } \\
\hline Nulliparous & 4 & $\begin{array}{l}2 \cdot 0 \\
8.5\end{array}$ & $\begin{array}{l}378 \\
347\end{array}$ & $2: 2$ \\
\hline \multicolumn{5}{|l|}{$\begin{array}{l}\text { Multiparous } \\
\text { Beagle }\end{array}$} \\
\hline Nulliparous & $\begin{array}{l}72 \\
83\end{array}$ & $\begin{array}{l}4 \cdot 0 \\
5 \cdot 2\end{array}$ & $\begin{array}{l}235 \\
283\end{array}$ & $\begin{array}{l}30: 39 \\
40: 24\end{array}$ \\
\hline
\end{tabular}

Table 3. Comparison of conceptions in bitches after natural insemination and artificial insemination with fresh or frozen semen (1972)

\begin{tabular}{|c|c|c|c|}
\hline & Natural & $\begin{array}{c}\text { Artificial } \\
\text { (fresh semen) }\end{array}$ & $\begin{array}{c}\text { Artificial } \\
\text { (frozen semen) }\end{array}$ \\
\hline $\begin{array}{l}\text { Number of bitches inseminated } \\
\text { Number of conceptions } \\
\text { Conception rate }\end{array}$ & $\begin{array}{l}23 \\
18 \\
78 \cdot 3 \%\end{array}$ & $\begin{array}{l}62 \\
40 \\
64 \cdot 5 \%\end{array}$ & $\begin{array}{l}38 \\
25 \\
65 \cdot 8 \%\end{array}$ \\
\hline
\end{tabular}

\section{REFERENCES}

Bendorf, P. \& Chung, N. (1958) Preservation of canine semen: preliminary observations. Am. F. vet. Sci. 2, 32-35.

Gill, H.P., Kaufman, C.F., Foote, R.H. \& KIRK, R.W. (1970) Artificial insemination of beagle bitches with freshly collected, liquid stored and frozen stored semen. Am. F. vet. Res. 31, 1807-1813. HARrop, A.E. (1956) A review of canine artificial insemination. F. Am. vet. med. Ass. 129, 564-567.

KIRK, R. (1959) Artificial insemination in the dog. Allied Vet. 30, 40-44. 
Nagase, H. \& Nrwa, T. (1964) Deep freezing bull semen in concentrated pellet form. Proc. 5th Int. Congr. Anim. Reprod. \& A.I., Trento 4, 410-415.

Seager, S.W.J. (1969) Successful pregnancies utilizing frozen dog semen. A.I. Digest 17, 6 and 16. Seager, S.W.J. \& Fletcher, W. (1973) Progress on the use of frozen semen in the dog. Vet. Rec. 92, 610. 